\title{
A long-term study of gentoo penguin (Pygoscelis papua) population trends at a major Antarctic tourist site, Goudier Island, Port Lockroy
}

\author{
Michael J. Dunn ${ }^{1}$ - Jaume Forcada ${ }^{1}$. Jennifer A. Jackson ${ }^{1} \cdot$ Claire M. Waluda ${ }^{1}$. \\ Camilla Nichol $^{2} \cdot$ Philip N. Trathan ${ }^{1}$
}

Received: 11 January 2018 / Revised: 12 September 2018 / Accepted: 24 September 2018 /

Published online: 6 October 2018

(c) The Author(s) 2018

\begin{abstract}
Gentoo penguins Pygoscelis papua breed at a number of sites at the West Antarctic Peninsula, including Goudier Island, Port Lockroy-the longest studied location for tourist-penguin interactions in the Antarctic. These penguins annually encounter some of the highest numbers of tourists in the whole of Antarctica. Using yearly count data from all ten colonies on Goudier Island, we report changes in long-term population size and breeding success over a 21 year period (1996/1997 to 2016/2017), documenting inter-annual variability in numbers of breeding pairs and chicks fledged (productivity). We found a $24.5 \%$ (1.4\% per annum) decrease in breeding pairs; similar declines were evident in breeding pairs at six colonies visited by tourists as well as at four unvisited colonies. Breeding success also declined, with chick numbers declining in visited $(53.7 \%, 3.8 \%$ per annum) and unvisited colonies $(59.8 \%, 4.6 \%$ per annum). While gentoo penguin numbers are increasing regionally, we reveal a recent decline in the Goudier Island population occurring simultaneous with increases in tourist numbers from 262 in 1996/1997 to 19,688 in 2016/2017. Analyses suggest a complex situation with different possible drivers of change. There was a significant negative effect of increasing air temperature and shifts in sea ice variables on breeding pairs. However, similar statistical support showed a significant link existed between year and visitors, with higher numbers of visitors negatively affecting penguin numbers. Based on our results we recommend increased precaution in management at Goudier Island, and initiation of similar studies at other frequently visited penguin sites in Antarctica.
\end{abstract}

Keywords Population $\cdot$ Decline $\cdot$ Monitoring $\cdot$ Tourism $\cdot$ Air temperature $\cdot$ Sea ice

Communicated by David Hawksworth.

Electronic supplementary material The online version of this article (https://doi.org/10.1007/s1053 1-018-1635-6) contains supplementary material, which is available to authorized users.

Michael J. Dunn

mdunn@bas.ac.uk

1 British Antarctic Survey, Natural Environment Research Council, Madingley Road, Cambridge CB3 0ET, UK

2 UK Antarctic Heritage Trust, High Cross, Madingley Road, Cambridge CB3 0ET, UK 


\section{Introduction}

Gentoo penguins (Pygoscelis papua) have a circumpolar range with an estimated global population of 387,000 breeding pairs (Lynch 2013). Important breeding sites occur along the West Antarctic Peninsula (WAP) and across the Scotia Sea (Harris et al. 2015; Lynch et al. 2012), where approximately $80 \%$ of the global population breeds (IUCN 2016). The WAP and Scotia Sea are both experiencing significant environmental change (Forcada et al. 2006; SCAR 2009; Turner et al. 2016), with increases in air (Turner et al. 2016) and ocean temperatures (Gille 2008) and reductions in the regional duration and extent of seasonal sea-ice (Stammerjohn et al. 2008a, b). Recent gentoo population surveys at a number of sites across the WAP and Scotia Sea showed different trends at different sites; some were stable while others increased, or expanded southwards (Baylis et al. 2013; Clucas et al. 2014; Ducklow et al. 2007; Dunn et al. 2016; Juáres et al. 2013; Lynch 2013; Lynch et al. 2008). Following a recent reappraisal of population trends, the gentoo penguin is currently designated as "Least Concern" by the IUCN, having previously been classified as "Near Threatened" in 2012 (IUCN 2016).

Changes in penguin population size are a useful indicator of ecosystem status (Boersma 2008; Che-Castaldo et al. 2017; Croxall et al. 2002; Forcada and Trathan 2009; Fraser et al. 1992; Hinke et al. 2007; Lynch et al. 2010; Lynch and LaRue 2014; Murphy et al. 2007; Trathan et al. 2007; Trivelpiece et al. 2011; UKAHT 2016). Currently, a number of ecological programmes exist that include gentoo penguins as one of the species monitored; this includes the Commission for the Conservation of Antarctic Marine Living Resources (CCAMLR) Ecosystem Monitoring Program, CEMP (CCAMLR 2004). CEMP records a range of parameters for penguins in order to monitor the status of the marine ecosystem in areas used by fisheries, to determine whether observed changes might be ascribed to fishery impacts or to natural environmental variation (Agnew 1997). At Goudier Island, we used CEMP protocols to monitor key penguin parameters. The standardised monitoring programme at Goudier Island was established during the 1996/1997 breeding season to assess the effects of tourist visitors on the gentoo population (Cobley and Shears 1999). Since then, numbers of breeding pairs and crèching chicks, as well as visitor numbers, were counted annually at all colonies.

Gentoo penguins first established breeding colonies at Goudier Island, Port Lockroy in 1985 (Cobley and Shears 1999; Trathan et al. 2008) and became a tourist attraction shortly thereafter. There are currently 10 colonies on Goudier Island and the site has become one of the most heavily visited tourist sites anywhere in the Antarctic, receiving an average of approximately 11,200 visitors per austral summer (November to March). In 2012/2013, more than 16,000 passenger landings took place on Goudier Island (Bender et al. 2016; IAATO 2017; Lynch et al. 2010). During the austral summer, tourist vessels visit Goudier Island nearly every day to view the penguins and the restored historical British Antarctic Survey (BAS) base which is currently managed and maintained by the UK Antarctic Heritage Trust (UKAHT 2016). The number of tourists landing on the WAP has increased dramatically since the late 1980s: between the 1989/1990 and 2013/2014 austral summers the number of visitors landing increased by $6 \pm 1 \%$ per annum (Bender et al. 2016). The first tourist ships arrive at Goudier Island and nearby Jougla Point as early as mid-November (15 November in 2016), and daily visits continue until late February or March (28 February in 2017, 4 March in 2016), resulting in a complete overlap of tourist visits across the entire breeding season of the resident gentoo penguins (Black 2016; Cobley and Shears 1999). Tour ships visiting Goudier Island frequently incorporate visitor landings at nearby Jougla 
Point where a maximum of 100 people are permitted to land at a time (see http://www.ats. aq/devAS/ats_other_template.aspx?lang=e\&id=168cbdd8-56ae-45ad-8682-cdb7196f75 4e). Each visit to Goudier Island is carefully managed by UKAHT staff in accordance with current International Association of Antarctica Tour Operators (IAATO) visitor guidelines and the Antarctic Treaty System (ATS 2016; IAATO 2017; UKAHT 2016): a maximum of 60 visitors are permitted ashore at any one time and they are only permitted to travel along designated pathways under the supervision of UKAHT staff and ship-based guides. Nevertheless, the small size of the island makes it inevitable that visitors and station personnel are regularly within very close proximity (less than several metres) of nesting or transiting gentoo penguins and their chicks, despite a general recommendation of a $5 \mathrm{~m}$ minimum approach distance (IAATO 2017).

An initial study by Cobley and Shears (1999) found that gentoo penguin breeding success at Goudier Island during the 1996/1997 austral summer was similar to that elsewhere in the region, concluding that tourist disturbance was unlikely to have had an impact in that season. A more comprehensive study by Trathan et al. (2008), using data from 12 years (1996/1997-2007/2008), found high inter-annual variability in numbers of breeding pairs and observed productivity (number of chicks divided by number of nests with eggs), a result that reflects gentoo behaviour elsewhere (Holmes 2007; Putz et al. 2001). Six of the 10 Goudier Island colonies are directly visited by tourists, while four colonies are not. However, penguins nesting in these four colonies have to move through areas accessed by visitors to transit to and from the sea. Trathan et al. (2008) reported that breeding numbers in two of the six visited colonies declined significantly but breeding success remained unchanged, and interpreted this as likely due to small scale movement of breeding pairs between locally-situated colonies, as is commonly recorded in this species (Bost and Jouventin 1990).

The programme at Goudier Island is the longest-running study measuring potential tourist disturbance to breeding penguins in the Antarctic. Each year large numbers of tourists visit penguin breeding sites in Antarctica (Bender et al. 2016; IAATO 2017). Thus, the ongoing monitoring of Goudier Island remains of high conservation and management value. Here we present a 21-year dataset (1996/1997 to 2016/2017); data were collected in a consistent manner and conformed to the CEMP methodology. We compare the colonies visited by tourists with those not directly visited. In addition, we examine the influence of environmental variability and compare our observations with records from a neighbouring breeding site at Jougla Point on Wiencke Island, as well as with other sites within the local region (within $50 \mathrm{~km}$ range).

\section{Materials and methods}

\section{Study site and species}

This study took place at Goudier Island, Port Lockroy, Palmer Archipelago (644ㅇ's, $63^{\circ} 29^{\prime} \mathrm{W}$, Fig. 1). Goudier Island, $(\sim 200 \times 125 \mathrm{~m})$, is predominantly flat, exposed bedrock and dominated by the restored BAS base (Fig. 1). At this site gentoo penguins breed in 10 colonies varying in size from $<5$ to 231 pairs. Six colonies, named as "Boat", "Base", "Mast", "Screen", "Nissen" and "Anemometer" are located either adjacent to or in close proximity of the restored base buildings which are also visited by tourists (Fig. 1). Four colonies (Control 1-4) are located in the east of the island and not visited by tourists and 


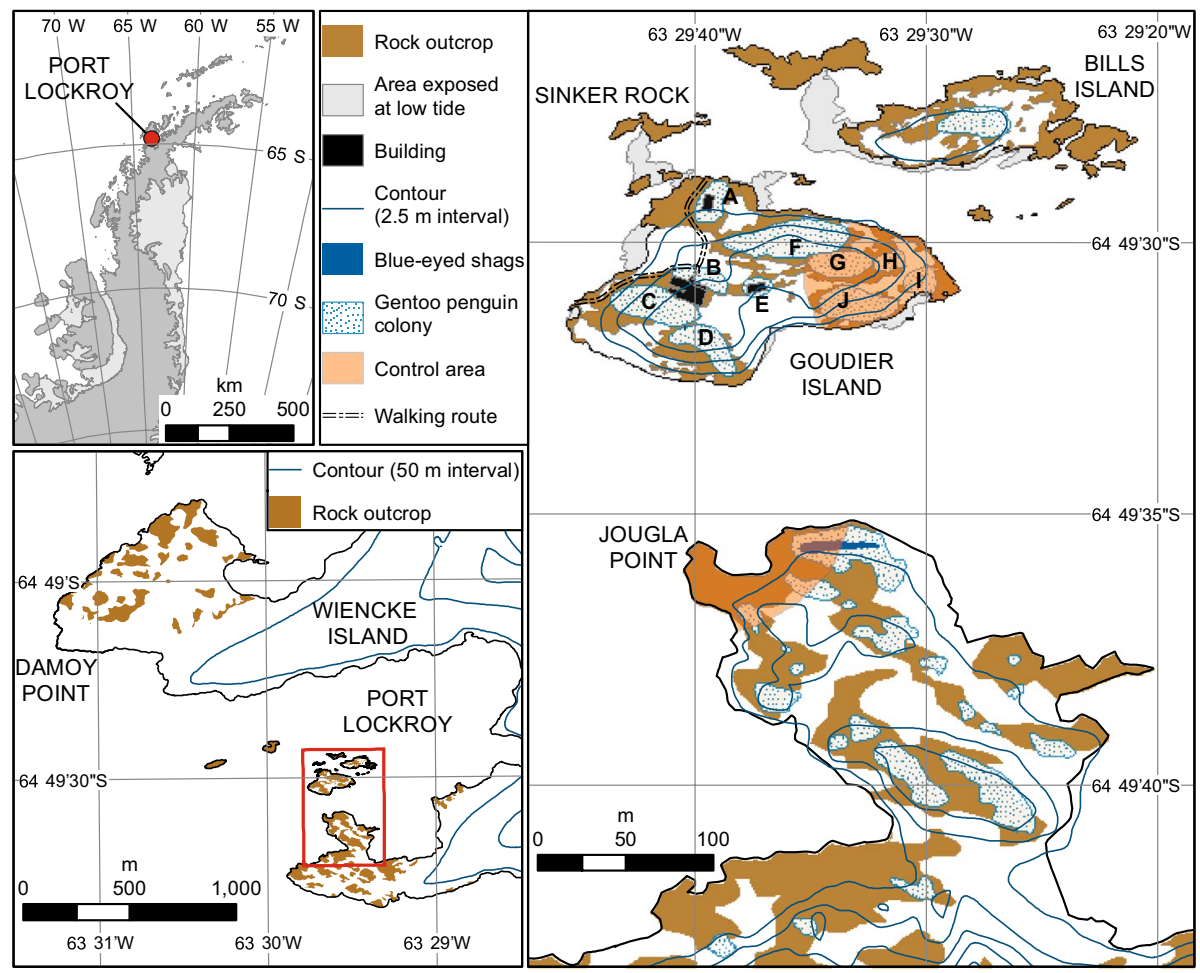

Fig. 1 Location of Goudier Island and Jougla Point, Port Lockroy including distribution of gentoo penguin breeding colonies and restored base. Note, for colonies: $A$ Boat, $B$ Base, $C$ Mast, $D$ Screen, $E$ Nissen, $F$ Anemometer, $G$ Control 1, $H$ Control 2, I Control 3, $J$ Control 4

rarely by base staff. However, penguins nesting here encounter tourists on their way to and from the sea but remain otherwise undisturbed except for annual pair, chick and crèche counts (Fig. 1).

\section{Survey methods}

Each colony on Goudier Island was defined as a distinct assemblage of nests clearly separated from neighbouring groups. All colonies were surveyed using direct ground count methods (Trathan et al. 2008) as set out in the CEMP Standard Methods (CCAMLR 2004). Fixed counting methods over successive years provided consistency both in data collection and also in disturbance levels. Annual breeding chronology dates were established (CEMP Method A9) using the "Mast" colony from 1996/1997 to 2007/2008 and the "Screen" colony after 2008/2009, as recommended by Trathan et al. (2008). Annual trends in population size (CEMP Method A3A) and estimated breeding success (CEMP Method A6C) were established for all colonies. Method A3A involves counting all occupied nests approximately 1 week after $95 \%$ of all nests in the chronology colony have at least one egg. Method A6C involves two counts: the first when hatching has ended at which time all chicks in nests are counted in each colony; the second count is made once chicks have formed crèches and the total number of chicks on Goudier is recorded. 
All surveys were carried out by a minimum of two field staff: personnel either entered a specific colony (necessary for Method A9) or observed from colony peripheries using a tally counter, (in which case all surveys were repeated a minimum of three times until the counts were within $10 \%$ and the mean count utilised for further analysis). Care was taken to keep any disturbance to a minimum: during surveys breeding birds rarely left their nests and those that did returned almost immediately.

We also reviewed gentoo pair data from Jougla Point, a rocky peninsula located at the western end of Wiencke Island, approximately $150 \mathrm{~m}$ from Goudier Island $\left(64^{\circ} 50^{\prime} \mathrm{S}\right.$, $63^{\circ} 29^{\prime}$ W, Fig. 1) and from seven other colonies within approximately $50 \mathrm{~km}$ of Goudier Island (Damoy Point, Biscoe Point, Cuverville Island, Danco Island, Georges Point, Useful Island, Waterboat Point, Supplementary Fig. S1). All count data for these seven colonies and Jougla Point were downloaded from the Mapping Application for Penguin Populations and Projected Dynamics website (MAPPPD, http://www.penguinmap.com) where they are publicly available (Humphries et al. 2017), data in MAPPPD being the most comprehensive available. Due to logistic constraints surveys at Jougla Point were carried out opportunistically between 1996/1997 and 2016/2017 (Humphries et al. 2017). All data generated during this study are available within this published article and its supplementary information files.

\section{Data analysis}

Annual tourist landing numbers for Goudier Island were recorded by UKAHT personnel and compared with penguin population size and breeding success. We used generalised additive models (GAMs) to assess inter-annual and temporal trends and visitor effects on the number of nests and chick counts respectively. Nesting penguins $(N)$ were a proxy for annual number of breeders and chick counts $(C)$ a proxy for productivity/breeding success $(f)$, and both parameters were assumed to follow a Tweedie distribution (Tweedie 1984). For productivity, $C \sim \mathrm{Tw}_{\mathrm{p}}\left(N_{t} f_{t}\right)$, the model likelihood, $L_{\mathrm{P}}(\mathbf{C}, \mathbf{N} \mid \mathbf{f})$ assumed that the total number of chicks counted in year $t$ depended on the number of nests and their productivity. While $N$ and $C$ are correlated, we also analysed the number of breeders independently as we were less concerned about the population dynamics of the study site than the aspects that affect its conservation status.

The main effects considered were type of colony (control vs. visited), number of visitors, season, and environmental variables; the latter included surface air temperature and a number of variables (see below) related to the sea ice state and year. Only models with sea ice variables that were not highly correlated were fitted to avoid collinearity effects. Then, model selection accounted for the best set of variables amongst all possible modelling options. The chosen variables represented collectively how the sea ice environment might affect the current penguin breeding season and were selected from previous analyses of the best predictors of penguin population dynamics (e.g. Forcada et al. 2006). Sea ice can reduce or prevent access to breeding sites and foraging sites; precipitation depends on air temperature and can affect breeding success through nest burial by snow or flooding from snow-melt or rainfall (Lishman 1985; Forcada et al. 2006; Forcada and Trathan 2009). Monthly surface air temperatures were obtained from Faraday/Vernadsky research station records, which is the closest long term record available (data available at the British Antarctic Survey; https://legacy.bas.ac.uk/met/READER/surface/Faraday.12.temperatur e.html). Sea ice variables were obtained from the US National Snow and Ice Data Center (NSIDC) (http://nsidc.org/), using daily images of sea ice concentrations from Nimbus-7 
SMMR and DMSP SSM/I-SSMIS Passive Microwave Data, Version 1 (Cavalieri et al. 1996). To calculate the seasonal sea ice cycle, sea ice data local to Goudier Island were selected with a polygon described by coordinates $-62.53,-62.55 ;-61.26,-63.75$; - 65.11, - 66.24; - 68.44, - 64.92; - 66.54, - 64.04; and - 64.63, - 63.28 of longitude and latitude. We chose a sea ice minimum threshold of $15 \%$ for consistency with previous studies using the same data sets; this concentration is the minimum reliably detectable with satellite imagery and is used to track the ice edge (Stammerjohn et al. 2008a, b). Sea ice variables included; (1) day of advance: first day when sea ice concentration exceeds $15 \%$ for at least 5 consecutive days; (2) day of retreat: first day when sea ice concentration remains $<15 \%$ until end of period; (3) ice season duration: the total number of sea-ice days (between day of advance and retreat); (4) actual ice days: number of days sea ice was present in the polygon area; (5) minimum sea ice extent: minimum $(<15 \%)$ sea ice concentration reached within the polygon area; (6) sea ice minimum: day of the year when the sea ice extent is at its lowest; (7) maximum sea ice extent: maximum \% concentration of sea ice within the polygon area; and (8) sea ice maximum: day of the year when sea ice reaches its largest extent within the polygon area.

Models for number of breeders and productivity were fitted as

$E\left(N_{i}\right)=\exp \left[X_{i} \beta+\sum_{k} s_{k}\left(z_{i k}\right)\right]+\epsilon_{i}$ and $E\left(C_{i}\right)=N_{i} \exp \left[X_{i} \beta+\sum_{k} s_{k}\left(z_{i k}\right)\right]+\epsilon_{i}$ respec-

tively, where $X_{i}$ is a model matrix with a vector $\beta$ of parametric terms, $s_{k}\left(z_{i k}\right)$ one-dimensional smoothers of $k$ continuous variables, and $\epsilon_{i}$ a residual error term.

Models (Supplementary Table S1 and S2) were implemented with methods in software R package mgcv (Wood 2006). Fitted models retained parametric effects and smoothers (thin plate regression splines) that increased the amount of deviance explained, and reduced AIC (also BIC) scores. These scores were also good indicators of best smoothing parameters (Wood et al. 2016). Diagnostic information on the results and fitting was obtained from residual plots and tests implemented in function gam.check of package $m g c v$.

In Tweedie models, for any random variable $Y$, the variance $\operatorname{var}(Y)$ relates to the mean $\mathrm{E}(Y)$ with a power law, $\operatorname{var}(Y)=a[E(Y)]^{p}$, where $a$ and $p$ are positive constants. Special cases are $p=0, p=1$, and $p=2$, corresponding to a Normal, Poisson and Gamma distributions respectively (Tweedie 1984). Here, the best value for $p$, constrained between 1 and 2 , was selected during the fitting process with an optimisation method implemented in function $t w$ of $m g c v$.

\section{Results}

\section{Population trends}

The total population of gentoo penguin breeding pairs on Goudier Island decreased by 24.5\% (1.4\% per annum) between 1996/1997 and 2016/2017 (Fig. 2, Table 1). During the early years (1996/1997 to 2000/2001), overall pair numbers increased by $25 \%(5.6 \%$ per annum), before decreasing in $2001 / 2002$ by $55.6 \%$ (Fig. 2, Table 1). The counts in $2001 / 2002$ represent the lowest number recorded in any season and are likely to be due to the heavy snowfall in that year (Trathan et al. 2008). Although the population recovered by $96.5 \%$ in the $2002 / 2003$ season, overall numbers of breeding pairs subsequently decreased by $30.8 \%$ (2.1\% per annum) to $2016 / 2017$ (Fig. 2, Table 1). 


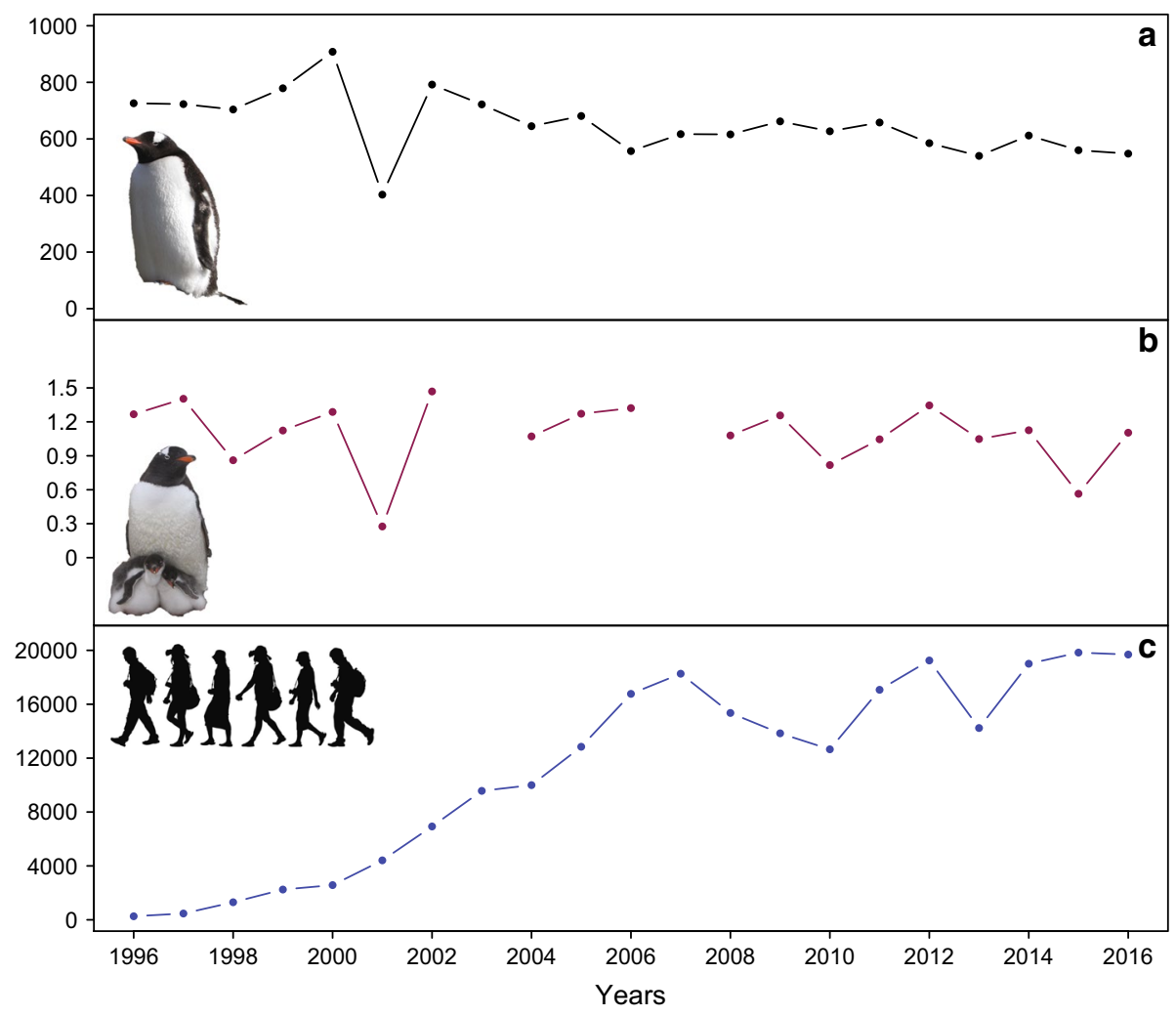

Fig. 2 Trends in gentoo penguins and tourists at Goudier Island, 1996/1997-2016/2017. a Breeding pairs counted annually in all colonies combined. b Breeding productivity (chicks/breeding pairs) in all colonies combined. c Total numbers of visitors landed at Goudier Island (IAATO 2017)

There was a long-term negative trend for total number of nests. The total number of nests counted each breeding season was best explained by type of colony, the effects of air temperature and sea ice maximum and an interaction term of year and number of visitors, (Supplementary Fig. S2). Nest numbers were negatively correlated with air temperature and positively correlated with sea ice maximum (Supplementary Fig. S2), although the sparseness of the data along the axis of the partial smoother plot, particularly the influence of the largest values of air temperature and sea ice maximum, indicate the potentially strong effects of a few extreme years. The interaction of year and visitors was highly significant $(p<0.002)$, and more recent years with higher numbers of visitors had a more negative effect on numbers of active nests (Supplementary Table S2). The relationship between number of nests and year was linear, $(-0.08689 ; \mathrm{SD}=0.02589 p=0.00192$; model 25 in supplementary Table S2). This negative trend corresponded to unaccounted temporal variation, once the effects of sea ice and air temperature were accounted for. However, the best model (model 30 in Supplementary Table S2) included an interaction term (not depicted in Supplementary Fig. S2) between season and number of tourists $(-8.825 \mathrm{e}-06$, $p=0.00157$ ). This indicated that the number of active nests decreased with season as the number of visitors increased. Assuming average environmental conditions and constant visitor numbers $(n=5000)$, the number of active nests would decline by $13 \%$ over 21 
Table 1 Total pair numbers and breeding productivity of gentoo penguins, Goudier Island, Port Lockroy $1996 / 1997-2016 / 2017$

\begin{tabular}{|c|c|c|c|c|c|}
\hline Season & Nests occupied & Date of pair count & Chicks counted & $\begin{array}{l}\text { Date of chick } \\
\text { count }\end{array}$ & $\begin{array}{l}\text { Breeding pro- } \\
\text { ductivity (chicks/ } \\
\text { occupied nest) }\end{array}$ \\
\hline $1996 / 1997$ & 726 & 6 Dec. 1996 & 920 & 14 Feb. 1997 & 1.2 \\
\hline $1997 / 1998$ & 723 & 1 Jan. 1998 & 1015 & 18 Feb. 1998 & 1.4 \\
\hline $1998 / 1999$ & 704 & 30 Nov. 1998 & 606 & 2 Feb. 1999 & 0.8 \\
\hline $1999 / 2000$ & 779 & 9 Dec. 1999 & 875 & 15 Feb. 2000 & 1.1 \\
\hline $2000 / 2001$ & 908 & 7 Dec. 2000 & 1169 & 6 Feb. 2001 & 1.2 \\
\hline $2001 / 2002$ & 403 & 4 Feb. 2002 & 111 & 25 Feb. 2002 & 0.2 \\
\hline $2002 / 2003$ & 792 & 3 Dec. 2002 & 1163 & 16 Jan. 2003 & 1.4 \\
\hline $2003 / 2004$ & 722 & 7 Dec. 2003 & & & \\
\hline $2004 / 2005$ & 645 & 7 Dec. 2004 & 691 & 17 Feb. 2005 & 1.0 \\
\hline $2005 / 2006$ & 681 & 17 Dec. 2005 & 866 & 27 Jan. 2006 & 1.2 \\
\hline $2006 / 2007$ & 557 & 11 Dec. 2006 & 736 & 22 Jan. 2007 & 1.3 \\
\hline $2007 / 2008$ & 617 & 11 Dec. 2007 & & & \\
\hline $2008 / 2009$ & 616 & 13 Dec. 2008 & 665 & 1 Feb. 2009 & 1.0 \\
\hline $2009 / 2010$ & 662 & 3 Dec. 2009 & 832 & 11 Feb. 2010 & 1.2 \\
\hline $2010 / 2011$ & 627 & 22 Dec. 2010 & 513 & 25 Feb. 2011 & 0.8 \\
\hline $2011 / 2012$ & 658 & 28 Nov. 2011 & 688 & 9 Feb. 2012 & 1.0 \\
\hline $2012 / 2013$ & 585 & 20 Dec. 2012 & 787 & 17 Dec. 2013 & 1.3 \\
\hline
\end{tabular}

seasons. If the number of visitors was 10,000 , the decline would be $25 \%$ over the same period. We tested for density dependence (effect "nest_1" in Supplementary Table S2) but this did not improve the fit of the best models and the effects were non-significant.

Similar patterns of population change occurred between the visited colonies (Boat, Base, Mast, Screen, Nissen and Anemometer) and unvisited colonies (Fig. 3, Supplementary Table S3), with several periods of distinct change. Both types of colony exhibited population increases from $1996 / 1997$ to $2000 / 2001$, followed by an exceptionally poor year in $2001 / 2002$, and immediate recovery in $2002 / 2003$. They subsequently underwent periodic fluctuations, with an overall decline in breeding pairs to 2016/2017. For the visited colonies, the overall pattern between 1996/1997 and 2016/2017 was a decline in numbers of $24.3 \%$ (1.4\% per annum, Fig. 3). Unvisited colonies showed a similar decline of $25.3 \%$ (1.5\% per annum) from 1996/1997 (Fig. 3).

\section{Breeding success}

Total breeding productivity across all ten colonies on Goudier Island varied between $13.4 \%$ and $73.4 \%$ ( 0.2 and 1.4 productivity, calculated as number of chicks crèched per breeding pair) from 1996/1997 to 2016/2017 (Fig. 2, 4, Supplementary Tables S3, S4). However, there was an overall decline over time (Fig. 4).

Of the eight sea ice variables considered, sea ice minimum and sea ice maximum were the most correlated with breeding success (Fig. 2, 4, Supplementary Fig. S2). Sea ice maximum was positively correlated with day of advance (Pearson's $r=0.734 p<0.001$ ) and was negatively correlated with sea-ice season duration and sea-ice duration (Pearson's 


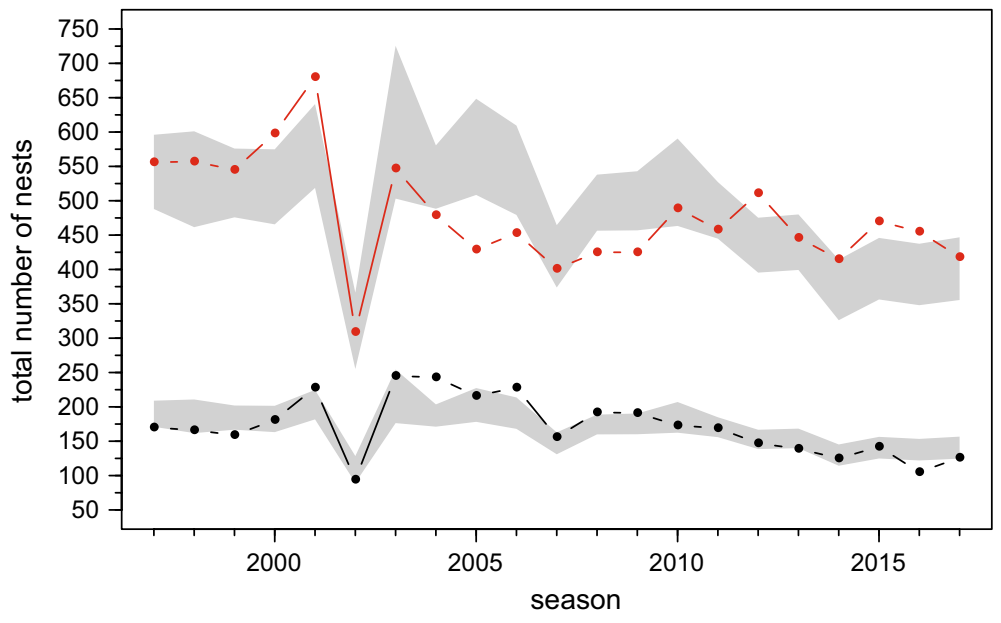

Fig. 3 Total number of gentoo penguin nests counted by season split by colony type (control/not visited = black dots, visited red dots). The grey bands are based on the seasonal prediction of nest counts and depict the temporal and environmental trends by colony type according to the best fitting GAM model. Confidence bands are based on $95 \%$ confidence interval prediction

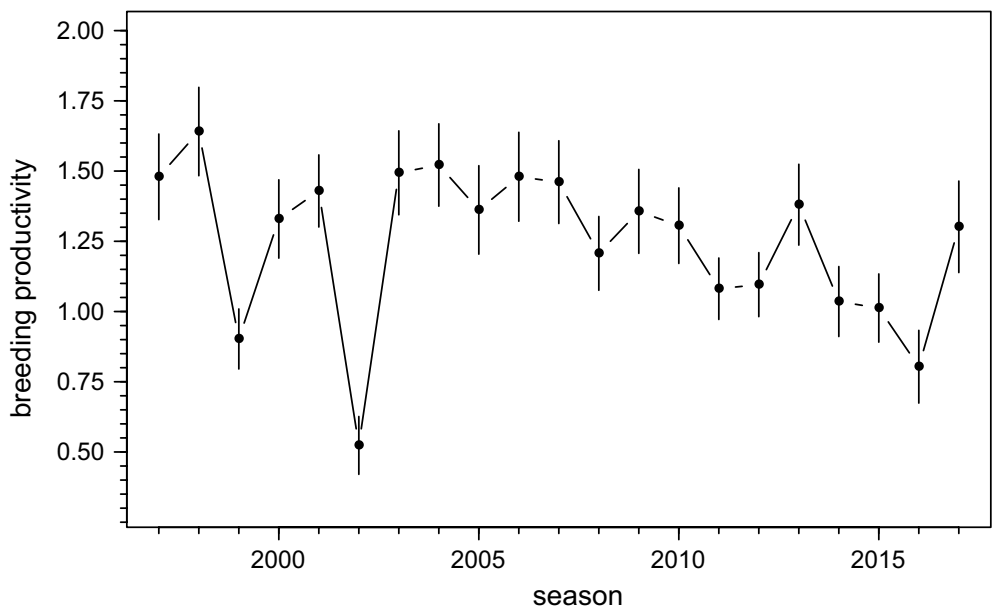

Fig. 4 Best-fitting GAM model prediction of total gentoo penguin breeding productivity (chicks/breeding pairs) by season for all colonies combined at Goudier Island. Vertical bars are 95\% confidence levels

$r=-0.576 p<0.007$ and $-0.586, p<0.006$ respectively, Supplementary Fig. S2). After accounting for the long-term trend, the variation in breeding success was best explained by sea ice variables. It had a nonlinear relationship with sea ice minimum and sea ice maximum (Supplementary Fig. S2), although the sparseness of the data along the axes of the partial smoother plots (Supplementary Fig. S2) does not suggest any obvious environmental pattern. Based on the best models, trends in breeding success did not differ between visited and unvisited colonies (Fig. 5). 


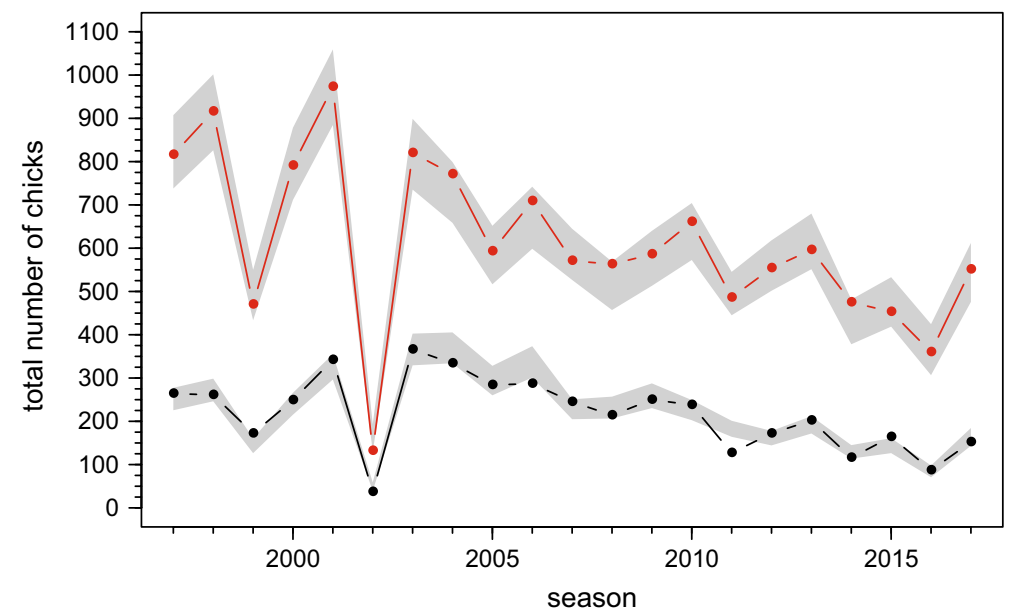

Fig. 5 Gentoo penguin total chick numbers recorded each season at Goudier Island split by colony type ( control = black dots, visited $=$ red dots). The grey bands are based on the seasonal prediction of nest counts and depict the temporal and environmental trends by colony type according to the best GAM model. Confidence bands are based on $95 \%$ confidence interval prediction

Between 1996/1997 and 2016/2017 breeding productivity in the four unvisited colonies showed inter-annual variation of between 19.6 and $78.6 \%$ (0.39-1.57 productivity, Fig. 5, Supplementary Table S4) while breeding productivity at the six visited colonies varied between 21.4 and $82.2 \%$ (0.4 and 1.6 productivity, Fig. 5, Supplementary Table S4). Over this time, breeding productivity declined across the four unvisited colonies by $46.3 \%$ from 1.55 to 0.83 productivity, and also declined across the visited colonies by $38.8 \%$ from 1.47 to 0.90 productivity (Fig. 5).

\section{Neighbouring colonies}

At Jougla Point (Fig. 1), the number of breeding pairs declined from 1595 to 1116 or $30 \%$ (1.9\% per annum) between 1996/1997 and 2015/2016 (Supplementary Table S5) and chick numbers declined by $22.6 \%$ (1.5\% per annum) from 2206 to 1708 between 1997/1998 and 2014/2015 (Humphries et al. 2017).

At seven other gentoo penguin colonies (Biscoe Point, Cuverville Island, Danco Island, Damoy Point, Georges Point, Useful Island and Waterboat Point) the number of breeding pairs increased in all except Useful Island, which declined by $2.7 \%$ between 2004/2005 and 2015/2016 (Supplementary Fig S1, Table S5, Humphries et al. 2017). Over the time period when most colonies were surveyed (2008/2009 and 2015/2016) the Damoy Point population decreased by $0.5 \%$ per annum (Goudier Island decreased by $1.4 \%$ per annum), but over the full survey period (1998/1999 to $2015 / 2016$ ), a small increase was recorded at this location. The other six colonies increased by between 23.6 and $57.1 \%$ overall, an increase of between 3.0 and $6.5 \%$ per annum (Fig. 3, Supplementary Table S5, Humphries et al. 2017). 


\section{Tourist numbers}

The overall number of visitors landing at Goudier Island increased by $7414.5 \%(21.6 \%$ per annum) between 1996/1997 and 2016/2017 (Fig. 2, Supplementary Table S6). There was an initial increase of $6871.4 \%$ (38.6\% per annum) from 262 to 18,265 people up to $2007 / 2008$, a subsequent $30.7 \%$ decrease to 12,654 people in $2010 / 2011$ and a second period of increase of $52.1 \%$ (21.0\% per annum) to 2012/2013 (Fig. 2, Supplementary Table S6). Although visitor numbers declined by 5014 over a single subsequent season $(2013 / 2014)$, a third period of increase $(38.3 \%, 10.8 \%$ per annum) followed up to 2016/2017 (Fig. 2, Supplementary Table S6). There was no statistical correlation between the number of visitors and the selected sea ice variables.

Jougla Point experienced an even more substantial increase in visitors: between $1996 / 1997$ and $2007 / 2008$ the number of people landing increased by $43.3 \%$ per annum, from 102 to 11,887 (Table 2, IAATO 2017). Subsequently visitor numbers declined by $30.4 \%$ (4.0\% per annum) up to 2016/2017. Overall there has been an increase of $22.0 \%$ per annum in the number of visitors landing at Jougla Point between 1996/1997 and 2016/2017 (Supplementary Table S6, IAATO 2017).

Visitor numbers available for five gentoo penguin colonies located within $50 \mathrm{~km}$ of Goudier Island (Cuverville Island, Danco Island, Damoy Point, Useful Island and Waterboat Point) all increased over the period 2001/2002 to 2016/2017 (Supplementary Fig. 2, Table S7, IAATO 2017). Over this 17 year period the number of people landed at all of these sites increased by 4.5 to $36.1 \%$ per annum.

\section{Discussion}

Our study focuses on the longest-running study examining visitor numbers and penguin population processes in the Antarctic. The dynamics of the gentoo colonies on Goudier Island are of interest in themselves, being situated within one of the fastest warming parts of the planet. That said, the study was initiated to explore interactions between visitors and penguins, so in this paper we focus much of our discussion upon this issue.

\section{Population trends}

The total number of gentoo penguin breeding pairs recorded on Goudier Island and at Jougla Point varied considerably between years but has fallen substantially at both sites since 1996/1997. Breeding success at these two sites also decreased over the same period. However, the population decreases at both Goudier Island and Jougla Point contrast with the majority of recent surveys at other gentoo breeding sites across the WAP/Scotia Arc. Excluding Goudier Island and Jougla Point, the general pattern has been broadly one of stable or increasing penguin populations and a gradual extension southward of the breeding range of this species (Baylis et al. 2013; Casanovas et al. 2015; Clucas et al. 2014; Ducklow et al. 2007; Dunn et al. 2016; Forcada et al. 2006; Humphries et al. 2017; IUCN 2016; Juáres et al. 2013; Lynch et al. 2012, 2008). In reviewing other study sites where potential tourism impacts are high, we found that three gentoo penguin colonies located within $50 \mathrm{~km}$ of Goudier Island (Cuverville Island, Danco Island and Waterboat Point) have all shown increasing numbers of breeding pairs in parallel to increasing numbers 
of tourists between 2001/2002 and 2015/2016. None of these three gentoo sites are however located in as small an area as Goudier Island in which tourists and breeding penguins overlap, suggesting caution in attempting to draw parallels. We also note that a study carried out between 2003/2004 and 2007/2008 at Petermann Island $\left(65^{\circ} 10^{\prime} \mathrm{S}, 64^{\circ} 10^{\prime} \mathrm{W}\right)$, approximately $48 \mathrm{~km}$ south east of Goudier Island and which also experiences high levels of tourism, found an increasing gentoo penguin population (Lynch et al. 2010). However the population trend at Peterman Island closely resembled that of Goudier Island over the same 5 year period to 2007/2008. More recent data from this location would therefore be valuable for determining whether the recent decline in gentoo penguin population size and breeding success at Goudier Island is occurring at this second, comparable site.

\section{Population drivers and future directions}

Stochastic environmental factors, such as snow coverage and air temperature can exert temporal and spatial effects, frequently on a local scale (Cobley and Shears 1999; Micol and Jouventin 2001; Southwell et al. 2013; Van Franeker et al. 2001). Sea ice, oceanographic and weather conditions are all known to influence penguin population size and breeding success (Boersma 2008; Forcada and Trathan 2009). Our models for nest counts suggested a negative effect of higher temperatures and a positive effect of day of maximum sea ice; the best model indicated negative effects during years of extreme sea ice and increased surface air temperature on numbers of gentoo breeding pairs and breeding success in visited and unvisited/control colonies at Goudier Island. These effects are consistent with similar observations in other parts of the range of this species and support results from the Petermann Island study (Lynch et al. 2010) where breeding success was significantly correlated with total December precipitation (rain and/or snow). Both findings are of particular interest given the increase in precipitation across the WAP (Lynch et al. 2010; Turner et al. 2005).

The best nest count model found the interaction of year and visitors was highly significant; recent years in which higher numbers of tourists visited Goudier Island had a more negative effect on numbers of gentoo breeding pairs both in visited and unvisited colonies. This decline was best modelled by a linear trend (variable "syear"). There was a strong correlation between decreasing numbers of penguin pairs and increasing numbers of tourists over time, potentially confounding the importance of both time and tourist effects on nest counts. However, the best model had only the interaction term, thus resolving this issue, and suggested that there was strong support for a negative effect of visitors on nest counts.

Between 1996/1997 and 2007/2008, Trathan et al. (2008) found a significant decline in breeding pairs (nests counted) in the colonies visited by tourists and stable or increasing pair numbers in the unvisited control colonies at Goudier Island. A similar trend was found by Lynch et al. (2010) at Petermann Island between 2003/2004 and 2007/2008, with gentoo penguin reproductive success lowest in colonies frequently visited by tourists, as opposed to colonies that remained visitor-free. Our results show a continuation of the declining trend in numbers of breeding pairs within the visited colonies, but also reveal an almost identical rate of pair decline in the unvisited colonies (a reduction of $24 \%$ and $25 \%$, respectively, over the entire 21 -year period). This represents a significant change at Goudier Island, and future surveys carried out at Petermann Island would be most useful in establishing whether such a change has also taken place on that island. The small size of Goudier Island makes a certain degree of close contact between penguins breeding in the control areas and humans inevitable, despite best efforts to minimalize disturbance to these 
control colonies. Regardless of colony location, most penguins enter and leave the water from several main sections of shoreline, most of which are located within the visited part of the island. They use common pathways across the island which again require birds from both visited and control colonies to travel through the "visited areas" (UK Antarctic Heritage Trust unpublished data). The unvisited control colonies are located less than $100 \mathrm{~m}$ from the main buildings and walkways that form the focal points for visiting tourist parties, and the boundary zone dividing these colonies from the rest of the island runs adjacent to control colony one and four, facilitating the approach of tourists to within several metres of penguins nesting in these colonies. Consequently penguin breeding pairs in both visited and unvisited colony areas may be equally susceptible to negative behavioural or physiological responses brought about by the continued season-long presence of large numbers of visitors (Bender et al. 2016; Holmes 2007; Southwell et al. 2013).

Practically all available penguin nesting areas on Goudier Island have been occupied by breeding pairs. Consequently it is plausible to assume that the carrying capacity (K) of the island has been reached, with pair numbers currently likely to be fluctuating around the maximum sustainable number. However, we found no significant effects of density dependence when testing as a possible explanatory variable. Trathan et al. (2008) noted the plausibility of movement by individual birds between colonies on Goudier Island and between Goudier Island and adjacent Wiencke Island (Jougla Point) as a likely cause of local scale variation in population size. The declining trend detected at both Goudier Island and Jougla Point in this study appears to dispel the possibility of such movement as the main driver of population decline.

During the 21 years of this study both Goudier Island and Jougla Point experienced a $22 \%$ per annum increase in visitor numbers, and are amongst the most intensively visited areas anywhere in the WAP (Bender et al. 2016; IAATO 2017; Lynch et al. 2010). For example, in 2015/2016 Goudier Island received a total of 19,834 visitors over a 112 day period; an average of 177 people every day, despite a further 16 tourist ships cancelling their planned visits due to increased levels of sea ice (UK Antarctic Heritage Trust unpublished data). This is a very significant increase from the 35-55 tourists visiting the same site every 1-2 days (262 people in total) in 1996/1997 (IAATO 2017) and represents a disproportionate growth in tourist numbers and visits relative to the rest of the WAP (Bender et al. 2016; IAATO 2017; Lynch et al. 2010). Although we found no statistical correlation between the number of tourists and sea ice variables, increased sea ice might affect the arrival of cruise ships to Goudier Island, although this would be unlikely during the summer months when tourist visits take place. Recent predictive analyses suggest likely further increases in the number of tourists visiting the Antarctic, including at Goudier Island and Jougla Point, particularly as winter sea ice continues to decline in extent and duration (Bender et al. 2016; Lynch et al. 2010; Stammerjohn et al. 2008a). However, given the time lag associated with scheduling additional tourist cruises, it is unlikely that additional cruises could be organised at short notice in any given year to take advantage of prevailing sea ice conditions. Thus, disentangling the impact of the presence of tourists from environmental factors may remain a complex problem, requiring more detailed data collection protocols than are currently in place.

Human disturbance can have a significant negative effect on Antarctic wildlife (Coetzee and Chown 2016). Stress to incubating birds, obstruction of foraging pathways and land routes to and from colonies, depressed recruitment at breeding sites and physiological disruption have all been cited as potential consequences of tourism close to sensitive penguin populations (Bender et al. 2016; Coetzee and Chown 2016; Ellenberg et al. 2006, 2007; Lynch et al. 2010; Trathan et al. 2015). Magellanic Spheniscus magellanicus, Humboldt 
S. humboldti and yellow eyed Megadyptes antipodes penguins exposed to human visitors all responded with elevated heart rates; the severity of disturbance and time taken for heart rate to return to normal was directly related to the length of exposure (Ellenberg et al. 2013), including at distances of up to $150 \mathrm{~m}$ (Ellenberg et al. 2006). However, such studies should be treated with caution when intimating cause and effect in our study due to variation in sensitivity to human disturbance between penguin species and location (Trathan et al. 2008; Villanueva et al. 2014; Walker et al. 2005). Future monitoring of physical and physiological responses, such as heart rate, hormonal levels or body temperature, amongst gentoo penguins at Goudier Island could help to determine if and to what extent penguins within the visited and control colonies are exhibiting stress symptoms (Bejder et al. 2009), although the feasibility of carrying out increased levels of fieldwork at study sites of such high tourist intensity would require careful evaluation.

\section{Conclusion}

Over the past 21 years there has been a significant change in the gentoo penguin population at Goudier Island and Jougla Point, Port Lockroy. However, the processes driving these local-scale changes remains unclear. Despite the evident decline in the numbers of breeding pairs and breeding success at both Goudier Island and Jougla Point, we advise caution when attempting to interpret the factors influencing these trends. Che-Castaldo et al. (2017) demonstrated that the effects of random fluctuating dynamics and "process noise" can significantly influence abundance shifts in penguin populations, particularly at the local scale of individual colonies, and subsequently complicate accurate interpretation of the drivers responsible. Our data suggest a degree of complexity, with gentoo penguin population trends at Goudier Island (and Jougla Point) influenced by a number of potentially subtle drivers acting together.

Given the high level of human visitation, on-going annual monitoring of the Goudier Island and Jougla Point gentoo penguin breeding populations should remain a high priority, including collecting information on numbers of visitors per day and length of visits to test for any specific visitor effects on each breeding stage (e.g. arrival, incubation, brood guard, crèche). Additional surveys using standard methodologies at other breeding sites of gentoo penguins within the Palmer Archipelago/WAP region would provide valuable comparisons and context to the changes taking place at Goudier Island (Che-Castaldo et al. 2017), where current population trends differ from those at some other regional sites. Noting the highly significant interactions between increasing human visitation and decreasing numbers of gentoo penguin breeding pairs at Goudier Island and Jougla Point, the current levels of tourist numbers could be seen in contradiction to a precautionary approach. Arguably, a potential annual cap on total numbers of tourists visiting Goudier Island and Jougla Point and restrictions to the landing season at settlement should be considered. Continued collection of meteorological data, such as air temperature and snow cover, would be useful to evaluate ongoing stochastic environmental factors (Southwell et al. 2013; Trathan et al. 2008; Van Franeker et al. 2001). Only by improving our understanding of the causes that manifest as population declines on both local and regional scales will we be able to implement management strategies to safeguard penguin populations at Port Lockroy and elsewhere, and balance the demands of the tourism industry with the needs of the penguins. 
Acknowledgements We thank all the staff of the United Kingdom Antarctic Heritage Trust and British Antarctic Survey (BAS) who have contributed to and supported the long-term penguin monitoring programme at Port Lockroy. We also thank Laura Gerrish for her mapping assistance and three reviewers for their helpful advice and comments. This study is part of the Ecosystems component of the British Antarctic Survey Polar Science for Planet Earth Programme, funded by The Natural Environment Research Council.

\section{Compliance with ethical standards}

Conflict of interest The authors declare that they have no conflict of interest.

Ethical approval All procedures performed in this study involving animals were in accordance with permits issued under the Antarctic Treaty Act (Antarctic Act 1994) and approved by the British Antarctic Survey Animal Ethics Committee. Permission for data collection was granted by the British Foreign and Commonwealth Office on behalf of HM Secretary of State, under Section 12 and 13 of the Antarctic Act, 1994, 2013.

Open Access This article is distributed under the terms of the Creative Commons Attribution 4.0 International License (http://creativecommons.org/licenses/by/4.0/), which permits unrestricted use, distribution, and reproduction in any medium, provided you give appropriate credit to the original author(s) and the source, provide a link to the Creative Commons license, and indicate if changes were made.

\section{References}

Agnew DJ (1997) The CCAMLR ecosystem monitoring programme. Antarct Sci 9:235-242

ATS (2016) Secretariat of the Antarctic treaty. http://www.ats.aq/e/ats_other_siteguidelines.htm. Accessed 17 Oct 2016

Baylis AMM, Crofts S, Wolfaardt AC (2013) Population trends of gentoo penguins Pygoscelis papua breeding at the Falkland Islands. Mar Ornithol 41:1-5

Bejder L, Samuels A, Whitehead H, Finn H, Allen S (2009) Impact assessment research: use and misuse of habituation, sensitisation and tolerance in describing wildlife responses to anthropogenic stimuli. Mar Ecol Prog Ser 395:177-185. https://doi.org/10.3354/meps07979

Bender NA, Crosbie K, Lynch HJ (2016) Patterns of tourism in the Antarctic Peninsula region: a 20-year analysis. Antarct Sci 28:194-203. https://doi.org/10.1017/S0954102016000031

Black CE (2016) A comprehensive review of the phenology of Pygoscelis penguins. Polar Biol 39:405-432. https://doi.org/10.1007/s00300-015-1807-8

Boersma PD (2008) Penguins as marine sentinels. Bioscience 58:597-607

Bost CA, Jouventin P (1990) Evolutionary ecology of gentoo penguins (Pygoscelis papua). In: Davis LS, Darby JT (eds) Penguin biology. Academic Press, San Diego, pp 85-112

Casanovas P, Naveen R, Forrest S, Poncet J, Lynch HJ (2015) A comprehensive coastal seabird survey maps out the front lines of ecological change on the western Antarctic Peninsula. Polar Biol 38:927-940. https://doi.org/10.1007/s00300-015-1651-x

Cavalieri DJ, Parkinson CL, Gloersen P, Zwally HJ (1996) Sea Ice Concentrations from Nimbus-7 SMMR and DMSP SSM/I-SSMIS passive microwave data, Version 1. NASA National Snow and Ice Data Center Distributed Active Center. Boulder, Colorado, USA. Accessed 17 May 2017

CCAMLR (2004) Standard methods for monitoring parameters of predator species. www.ccamlr.org. Accessed: 30 June 2017

Che-Castaldo C, Jenouvrier S, Youngflesh C, Shoemaker KT, Humphries G, McDowall P, Landrum L, Holland MM, Li Y, Ji RB, Lynch HJ (2017) Pan-Antarctic analysis aggregating spatial estimates of Adelie penguin abundance reveals robust dynamics despite stochastic noise. Nat Commun. https://doi. org/10.1038/s41467-017-00890-0

Clucas GV, Dunn MJ, Dyke G, Emslie SD, Levy H, Naveen R, Polito MJ, Pybus OG, Rogers AD, Hart T (2014) A reversal of fortunes: climate change 'winners' and 'losers' in Antarctic Peninsula penguins. Sci Rep 4:5024. https://doi.org/10.1038/srep05024

Cobley ND, Shears JR (1999) Breeding performance of gentoo penguins (Pygoscelis papua) at a colony exposed to high levels of human disturbance. Polar Biol 21:355-360. https://doi.org/10.1007/s0030 00050373 
Coetzee BWT, Chown SL (2016) A meta-analysis of human disturbance impacts on Antarctic wildlife. Biol Rev 91:578-596. https://doi.org/10.1111/brv.12184

Croxall JP, Trathan PN, Murphy EJ (2002) Environmental change and Antarctic seabird populations. Science 297:1510-1514

Ducklow HW, Baker K, Martinson DG, Quetin LB, Ross RM, Smith RC, Stammerjohn SE, Vernet M, Fraser W (2007) Marine pelagic ecosystems: the West Antarctic Peninsula. Philos Trans R Soc Lond B 362:67-94. https://doi.org/10.1098/rstb.2006.1955

Dunn MJ, Jackson JA, Adlard S, Lynnes AS, Briggs DR, Fox D, Waluda CM (2016) Population size and decadal trends of three penguin species nesting at Signy Island, South Orkney Islands. PLoS ONE 11:e0164025. https://doi.org/10.1371/journal.pone.0164025

Ellenberg U, Mattern T, Seddon PJ, Luna-Jorquera G (2006) Physiological and reproductive consequences of human disturbance in Humboldt penguins: the need for species-specific visitor management. Biol Conserv 133:95-106. https://doi.org/10.1016/j.biocon.2006.05.019

Ellenberg U, Setiawan AN, Cree A, Houston DM, Seddon PJ (2007) Elevated hormonal stress response and reduced reproductive output in Yellow-eyed penguins exposed to unregulated tourism. Gen Comp Endocrinol 152:54-63. https://doi.org/10.1016/j.ygcen.2007.02.022

Ellenberg U, Mattern T, Seddon PJ (2013) Heart rate responses provide an objective evaluation of human disturbance stimuli in breeding birds. Conserv Physiol 1:cot013. https://doi.org/10.1093/ conphys/cot013

Forcada J, Trathan P (2009) Penguin responses to climate change in the Southern Ocean. Glob Change Biol 15:1618-1630

Forcada J, Trathan PN, Reid K, Murphy EJ, Croxall JP (2006) Contrasting population changes in sympatric penguin species in association with climate warming. Glob Change Biol 12:411-423

Fraser WR, Trivelpiece WZ, Ainley DG, Trivelpiece SG (1992) Increases in Antarctic penguin populations-reduced competition with whales or a loss of sea ice due to environmental warming. Polar Biol 11:525-531

Gille ST (2008) Decadal-scale temperature trends in the Southern Hemisphere ocean. J Clim 21:47494765. https://doi.org/10.1175/2008JCLI2131.1

Harris CM, Lorenz K, Fishpool LDC, Lascelles B, Cooper J, Coria NR, Croxall JP, Emmerson LM, Fijn RC, Fraser WL, Jouventin P, LaRue MA, Le Maho Y, Lynch HJ, Naveen R, Patterson-Fraser DL, Peter H-U, Poncet S, Phillips RA, Southwell CJ, van Franeker JA, Weimerskirch H, Wienecke B, Woehler EJ (2015) Important bird areas in Antarctica 2015. BirdLife International and Environmental Research \& Assessment Ltd., Cambridge, p 313

Hinke JT, Salwicka K, Trivelpiece SG, Watters GM, Trivelpiece WZ (2007) Divergent responses of Pygoscelis penguins reveal a common environmental driver. Oecologia 153:845-855

Holmes ND (2007) Comparing king, gentoo, and royal penguin responses to pedestrian visitation. J Wildlife Manag 71:2575-2582. https://doi.org/10.2193/2005-715

Humphries GRW, Che-Castaldo C, Naveen R, Schwaller M, McDowall P, Schrimpf M, Lynch HJ (2017) Mapping application for penguin populations and projected dynamics (MAPPPD): data and tools for dynamic management and decision support. Polar Rec 53:160-166. https://doi.org/10.1017/ S0032247417000055

IAATO (2017) International Association of Antarctica Tour Operators. https://iaato.org/tourism-stati stics. Accessed 20 Oct 2017

IUCN (2016) IUCN Red List of Threatened species. www.iucnredlist.org Accessed 7 Dec 2016

Juáres MA, Santos MR, Mennucci JA, Rombolá E, Longarzo L, Coria NR, Carlini AR (2013) Better late than never? Internannual and seasonal variability in breeding chronology of gentoo penguins at Stranger Point, Antarctica. Polar Res 32:1. https://doi.org/10.3402/polar.v32i0.18448

Lishman GS (1985) The comparative breeding biology of Adèlie and chinstrap penguins Pygoscelis adeliae and Pygoscelis antarctica at Signy Island, South Orkney Islands. J Zool 205:245-263

Lynch HJ (2013) The gentoo penguin (Pygoscelis papua). In: Borboroglu PG, Boersma PD (eds) Penguins: natural history and conservation. University of Washington Press, Seattle, USA, pp 73-88

Lynch HJ, LaRue MA (2014) First global census of the Adélie penguin. Auk 131:457-466

Lynch HJ, Naveen R, Fagan WF (2008) Censuses of penguin, blue eyed shag Phalacrocorax atriceps and southern giant petrel Macronectes giganteus populations on the Antarctic Peninsula, 20012007. Mar Ornithol 36:83-97

Lynch HJ, Fagan WF, Naveen R (2010) Population trends and reproductive success at a frequently visited penguin colony on the western Antarctic Peninsula. Polar Biol 33:493-503

Lynch HJ, Naveen R, Trathan PN, Fagan WF (2012) Spatially integrated assessment reveals widespread changes in penguin populations on the Antarctic Peninsula. Ecology 93:1367-1377

Micol T, Jouventin P (2001) Long-term population trends in seven Antarctic seabirds at Pointe Geologie (Terre Adelie)_-human impact compared with environmental change. Polar Biol 24:175-185. https ://doi.org/10.1007/s003000000193 
Murphy EJ, Watkins JL, Trathan PN, Reid K, Meredith MP, Thorpe SE, Johnston NM, Clarke A, Tarling GA, Collins MA, Forcada J, Shreeve RS, Atkinson A, Korb R, Whitehouse MJ, Ward P, Rodhouse PG, Enderlein P, Hirst AG, Martin AR, Hill SL, Staniland IJ, Pond DW, Briggs DR, Cunningham NJ, Fleming AH (2007) Spatial and temporal operation of the Scotia Sea ecosystem: a review of large-scale links in a krill centred food web. Philos Trans R Soc Lond B 362:113-148. https://doi. org/10.1098/rstb.2006.1957

Putz K, Ingham RJ, Smith JG, Croxall JP (2001) Population trends, breeding success and diet composition of gentoo Pygoscelis papua, magellanic Spheniscus magellanicus and rockhopper Eudyptes chrysocome penguins in the Falkland Islands. Polar Biol 24:793-807. https://doi.org/10.1007/s003000100293

SCAR (2009) Antarctic climate change and the environment (ACCE) review report. https://www.scar.org/ policy/acce-updates/

Southwell C, McKinlay J, Low M, Wilson D, Newbery K, Lieser JL, Emmerson L (2013) New methods and technologies for regional-scale abundance estimation of land-breeding marine animals: application to Adelie penguin populations in East Antarctica. Polar Biol 36:843-856. https://doi.org/10.1007/s0030 0-013-1310-Z

Stammerjohn SE, Martinson DG, Smith RC, Iannuzzi RA (2008a) Sea ice in the Western Antarctic Peninsula region: spatio-temporal variability from ecological and climate change perspectives. Deep Sea Res Part II Top Stud Oceanogr 55:2041-2058

Stammerjohn SE, Martinson DG, Smith RC, Yuan X, Rind D (2008b) Trends in Antarctic annual sea ice reatreat and advance and their relation to El Nino-Southern Oscillation and Southern Annular Mode variability. J Geophys Res Oceans 113:1-20

Trathan PN, Forcada J, Murphy EJ (2007) Environmental forcing and Southern Ocean marine predator populations: effects of climate change and variability. Philos Trans R Soc Lond B 362:2351-2365

Trathan PN, Forcada J, Atkinson R, Downie RH, Shears JR (2008) Population assessments of gentoo penguins (Pygoscelis papua) breeding at an important Antarctic tourist site, Goudier Island, Port Lockroy, Palmer Archipelago, Antarctica. Biol Conserv 141:3019-3028. https://doi.org/10.1016/j.bioco n.2008.09.006

Trathan PN, Garcia-Borboroglu P, Boersma D, Bost CA, Crawford RJM, Crossin GT, Cuthbert RJ, Dann P, Davis LS, De La Puente S, Ellenberg U, Lynch HJ, Mattern T, Putz K, Seddon PJ, Trivelpiece W, Wienecke B (2015) Pollution, habitat loss, fishing, and climate change as critical threats to penguins. Conserv Biol 29:31-41. https://doi.org/10.1111/cobi.12349

Trivelpiece ZW, Hinke JT, Miller AK, Reiss CS, Trivelpiece SG (2011) Variability in krill biomass links harvesting and climate warming to penguin population changes in Antarctica. Proc Natl Acad Sci USA 108:7625-7628

Turner J, Colwell SR, Marshall GJ, Lachlan-Cope TA, Carleton AM, Jones PD, Lagun V, Reid PA, Iagovkina S (2005) Antarctic climate change during the last 50 years. Int J Climatol 25:279-294. https ://doi.org/10.1002/Joc.1130

Turner J, Lu H, White I, King JC, Phillips T, Hosking JS, Bracegirdle TJ, Marshall GJ, Mulvaney R, Deb P (2016) Absence of 21st century warming on Antarctic Peninsula consistent with natural variability. Nature 535:411-415. https://doi.org/10.1038/nature18645

Tweedie MCK (1984) An index which distinguishes between some important exponential families. In Statistics: applications and new directions. In: JK Ghosh, J Roy (eds) Proceedings of the Indian Statistical Institute Golden Jubilee International Conference, pp. 579-604. Indian Statistical Institute, Calcutta

UKAHT (2016) United Kingdom Antarctic Heritage Trust. http://www.ukaht.org/visit/visiting-port-lockr oy/. Accessed: 22 Nov 2016

Van Franeker JA, Creuwels JCS, Van der Veer W, Cleland S, Robertson G (2001) Unexpected effects of climate change on the predation of Antarctic petrels. Antarct Sci 13:430-439

Villanueva C, Walker BG, Bertellotti M (2014) Seasonal variation in the physiological and behavioral responses to tourist visitation in magellanic penguins. J Wildl Manag 78:1466-1476. https://doi. org/10.1002/jwmg.791

Walker BG, Boersma PD, Wingfield JC (2005) Physiological and behavioral differences in magellanic penguin chicks in undisturbed and tourist-visited locations of a colony. Conserv Biol 19:1571-1577. https ://doi.org/10.1111/j.1523-1739.2005.00104.x

Wood SN (2006) Generalized additive models: an introduction with R. Chapman and Hall/CRC Press, Boca Raton, FL

Wood SN, Pya N, Safken B (2016) Smoothing parameter and model selection for general models. J Am Stat Assoc 111:1548-1578 